Ensino, Saúde e Ambiente-V6 (2), pp.33-43, ago. 2013

\title{
DOENÇAS CAUSADAS POR FATORES AMBIENTAIS NA BAIXADA DO MUNICÍPIO DE SANTA TERESA - ES
}

\section{DISEASES CAUSED BY ENVIRONMENTAL FACTORS IN BAIXADA THE CITY OF SANTA TERESA - ES}

\author{
Marcus Vinicius Sandoval Paixão ${ }^{1}$, Gleides Pulcheira Paixão ${ }^{2}$; Polyana Pulcheira Paixão \\ ${ }^{1}$ Professor do IFES - Campus Santa Teresa, mvspaixao@bol.com.br \\ ${ }^{2}$ Professor do IFES - Campus Santa Teresa, gleidespaixao@bol.com.br \\ ${ }^{3}$ Medica Veterinária - CLIMEV, polyzinha_pp@hotmail.com
}

\section{RESUMO}

Objetivou-se diagnosticar as doenças existentes na baixada do município de Santa Teresa, causadas por contaminação do solo, água e ar, partir de uma metodologia exploratória, com pesquisa in loco, abordagem qualiquantitativa. Os resultados mostraram que as doenças ocorridas conseqüentes de contaminação da água, solo e ar, são próprias dos municípios considerados como agrícolas, sustentadas pela não observância dos hábitos de higiene e a falta de saneamento básico para a população, considerando a questão econômica e social, principalmente quando trabalhamos com o homem do campo, onde a principal atividade é a agricultura familiar de subsistência. $\mathrm{O}$ estudo mostrou a importância do aspecto social no processo educacional da população, onde a educação ambiental constitui-se fator de melhoria na saúde e qualidade de vida. Ao atingir seus objetivos a pesquisa confirmou a necessidade de educar a população para problemas oriundos da contaminação por fatores ambientais. Concluímos que a partir de um programa de educação ambiental, apresentado de forma simples e objetiva, ao alcance do conhecimento da clientela, podemos inserir conhecimentos de proteção e conservação do meio onde vivem, resgatando a qualidade de vida desejada.

Palavras chave: Educação Ambiental, Contaminação, Saúde coletiva, Doenças.

\begin{abstract}
ABSTACT
The intrution is the diagnosis of the disiases found in the low lands of the municipality of Santa Teresa, caused by the contamination of the ground, water and air, beginning with a exploratory methodology with a research "in loco" based on studies of adquate quality of questions. The result found came to the conclusion that the diseases caused by those factors are a consequence of the contamination of water, soil and air and are common in the municipalities known as agricultural, sustained by the dificiency of observation in the knowledge of hygiene and lack of basic information to those people, considering the economic and social situation of them, specially if we work with people , that have their principal activity in the agriculture for the family sustenance. The study showed the importance of social conduct in the educational behave of those people when the ambient education is considered as an important means for the development of health and quality of life. In searching their intention these studies have shown the necessity of giving those people the knowledge of problems that have their origin in the contamination induced by ambien causes. We come to the conclusion that beginning with a program besed on ambient education, presented in a simple and objective way and in the level of the necessery cognition for the protection and maintenance of the ambient where they live improving the required quality of life.
\end{abstract}

Keywords: Environmental Education, Pollution, Public health, Diseases 


\section{INTRODUÇÃO}

Até meados da década de 80, a maioria das grandes organizações internacionais, dos governos e dos pesquisadores com interesse nas questões relacionadas às condições de vida e saúde das populações, priorizavam as populações rurais, mais especificamente a dos países em desenvolvimento, como o foco principal de suas atenções e investimentos (Rossi-Espagnet et al., 1991). Isto se justificava pelo fato de boa parte dos centros urbanos, as cidades, virem oferecendo até então, melhores condições de garantir uma qualidade de vida adequada para seus habitantes.

A Educação Ambiental desponta no mundo atual como requisito básico para manutenção da vida no planeta, sua principal função é conscientizar à preservação do meio ambiente e sua conservação, ou seja, utilização sustentável.

Medina \& Santos (2003) citam que a Educação Ambiental é a incorporação de critérios sócio-ambientais, ecológicos, éticos e estéticos, nos objetivos didáticos da educação. Pretende construir novas formas de pensar incluindo a compreensão da complexidade e das emergências e inter-relações entre os diversos sistemas.

A saúde ambiental, antes vista como um prolongamento das biociências, aplicadas aos problemas de saúde publica, hoje se consolida como um campo interdisciplinar, recebendo importantes contribuições das ciências sociais e humanas.

Segundo Tessari (2003), desde o primeiro momento em que os seres humanos começaram a interagir com o mundo ao seu redor e a ensinarem seus filhos a fazerem o mesmo, estava havendo educação ambiental.

A própria globalização que rege os campos de um processo inovador e homogeneizador, tem produzido a aceleração dos ritmos de vida, conexões mundiais das esferas de produção e consumo, bem como a perda de identidades com os lugares.

Se o processo de globalização está ocorrendo no mundo de forma global é chegada a hora de nos preocuparmos com a importância do local em que vivemos, embasados na reeducação de valore s culturais, socais e econômicos.

Para a Organização Mundial de Saúde (OMS), saneamento pode ser entendido como o controle de fatores do meio físico do ser humano, que interferem ou podem interferir no bem estar físico, mental e social (Philippi Jr \& Malheiros, 2005). O saneamento tem por objetivo minimizar os danos ao meio ambiente que interferem na saúde da população, diminuindo a melhoria na comunidade visando a proteção e melhoria da qualidade de vida das comunidades respeitando suas características sócio 
culturais, econômicas e ambientais, através de tecnologias adequadas à própria comunidade. (Carvalho \& Oliveira, 1997).

É visto que o problema de saneamento precário é causador de diversas doenças, Aguiar (1998), cita que a ingestão da água contaminada pode causar: cólera, disenteria amebiana, disenteria bacilar, febre tifóide e paratifóide, gastroenterite, giardiase, hepatite infecciosa, leptospirose, paralisia infantil, salmonelose. Já, por contato, a água contaminada pode causar: escabiose (doença parasitária cutânea conhecida como Sarna), tracoma (mais freqüente nas zonas rurais), verminoses, tendo a água como um estágio do ciclo e esquistossomose.

Para Sirkis (2005), o uso irracional de agrotóxicos agride os trabalhadores rurais, agricultores e bóias-frias, que adoecem ou morrem por contaminação de produtos que têm seus princípios ativos proibidos nos países de origem das multinacionais que os comercializam no Brasil. Ele observa ainda que os lençóis freáticos e os poços artesianos são envenenados, atingindo seus filhos e mulheres. Isso cabe dizer que o agricultor e sua família ficam a mercê da falta de fiscalização do poder público, levando-o ao empobrecimento e ao êxodo rural.

Aguiar (1998) cita que a poluição do solo, gera resíduos sólidos e semi-sólido, provenientes das atividades de origem industrial, doméstica, hospitalar, comercial, agrícola e de varrição, lodos provenientes de sistemas de tratamento de água e gerados em equipamentos e instalações de controle de poluição e líquidos cujas particularidades tornem inviável o seu lançamento na rede pública de esgoto. A poluição do solo rural com os fertilizantes sintéticos são através de defensivos agrícolas e da salinização.

As descobertas feitas pelos cientistas, sobre os efeitos negativos que a poluição do ar causa à saúde do ser humano, trouxeram elementos novos para o estudo sobre o fenômeno da poluição do ar, como por exemplo, o fato de que pessoas expostas constantemente ao ar poluído podem vir a desenvolver determinadas doenças respiratórias, implicando em um quadro de sintomas que afeta vários órgãos, como o nariz e a garganta, potencializando o aparecimento e o aumento de casos de asma e sinusite, quando a poluição atinge os olhos, ocorre uma maior probabilidade de conjuntivite, nos brônquios, a poluição se manifesta com a predisposição à broncopneumonia, nos pulmões ocorre os riscos de enfisema e no coração, a poluição pode causar, dentre outras, o aumento nas doenças cardiovasculares (Vasconcelos et al., 2007). 
Mendes (2005) destaca a importância de desenvolver um cidadão consciente preocupado com os problemas ambientais e que tenha conhecimento e atitudes motivacionais, envolvimento e habilidades para trabalhar individual e coletivamente em busca de soluções para resolver os problemas atuais e prevenir os futuros.

Objetivou-se nesta pesquisa fazer um levantamento de dados com relação às principais doenças, conseqüentes de causas relacionadas ao meio ambiente, que atingem os distritos que compõem a baixada do município de Santa Teresa no estado do Espírito Santo, criando subsídios para a elaboração de uma proposta de programa de educação ambiental viável a realidade local de cada distrito.

\section{MATERIAL E MÉTODOS}

O município de Santa Teresa, localizado na região central serrana do Estado do Espírito Santo, foi o local escolhido para o estudo e desenvolvimento deste trabalho, sendo os trabalhos de pesquisa desenvolvidos na região da baixada do município.

Paixão (2009), cita que o município de Santa Teresa se localiza na zona serrana do Estado do Espírito Santo sendo que, sua parte mais alta fica a 1030 metros acima do nível do mar. A sede municipal a 665 metros de altitude tem sua posição geográfica determinada pelo Paralelo de $20^{\circ} 6{ }^{\prime}$, 02 " de latitude e $40^{\circ} 37^{\prime}$ 47" de longitude oeste.

A pesquisa não selecionou os postos de saúde da baixada de Santa Teresa, considerando que cada distrito só possui um posto de saúde, foram utilizados todos os postos existentes nos distritos estudados sendo, São João de Petrópolis (um posto), Várzea Alegre (um posto), Santo Antônio do Canaã (um posto), Vinte e Cinco de Julho (um posto), e visita a secretaria de saúde do município para confirmação dos dados obtidos e com dados coletadas entre os anos de 2006 e 2010.

A abordagem da amostra foi probabilística e representativa, sendo a coleta de dados feita através da catalogação das doenças causadas através da água, solo e ar contaminados, nos postos de saúde dos distritos estudados, e análise dos dados através da quantificação dos dados coletados, adotando o número de respostas para cada item.

Os dados desta pesquisa foram processados e organizados levando-se em consideração a freqüência de cada doença catalogada e o ano de sua ocorrência. 
Ensino, Saúde e Ambiente -V6 (2), pp. 33-43, ago. 2013

\section{ANÁLISE DOS RESULTADOS E DISCUSSÃO}

A tabela 1 transcreve os dados coletados na pesquisa de campo, após visitas às unidades de saúde dos distritos estudados, catalogados pela secretaria de saúde e transcritos para este trabalho.

O número maior de diagnoses recaem sobre as verminoses, principalmente esquistossomose e ancilostomose, com incidências significativas de ascaridíase Podemos afirmar que as ocorrências das verminoses citadas são advindas de fatores causais como a falta de tratamento da água, saneamento básico precário e a inexistência de educação sanitária. A educação ambiental nestes distritos carece de informações e ações que minimizem as conseqüências provenientes de um incorreto comportamento ambiental.

A verminose conhecida como ancilostomose ou amarelão, aparece em primeiro lugar de incidência em três distritos, 415 casos no total dos quatro distritos, com destaque para o distrito de Várzea Alegre com 120 casos, sendo o maior número de casos do estudo.

A Ancilostomose é produzido por dois tipos de vermes nematódeos: o ancilóstomo (Ancylostoma duodenale) e o Necátor (Necator americanus) (Spiller, 2010), O primeiro é comum no sul e o segundo no norte e nordeste do Brasil. As larvas desses vermes crescem na terra úmida e quente e é amplamente distribuída por todo o mundo, sendo endêmica nos países tropicais e subtropicais (Andrade, 2011).

Podemos detectar que as práticas agrícolas também concorrem como autor direto da transmissão deste verme. O contato direto das pessoas com o solo, faz com que, pela não utilização de calçados, aumentem a incidência da verminose.

A verminose conhecida como Esquistossomose, é transmitida através da água contaminada, principalmente de rios e lagos, em localidades sem saneamento básico ou com existência precária do mesmo, uma vez que a transmissão de tal doença se dá por meio do contato do homem com águas contaminadas com seu agente transmissor o Schistosoma mansoni, sendo que a contaminação da água é feita pelo próprio homem, à medida que o mesmo defeca diretamente no solo contaminando-o e expondo os dejetos à ação dos ventos e das chuvas, que arrastam as fezes contaminadas com ovos do verme para a água de modo a contaminá-la (Brasil, 2005).

Observamos a alta incidência da verminose, 371 casos, devido principalmente ao uso indevido destas águas em banhos em rios ou lagos. Nestes locais que predominam a atividade agrícola, observa-se que o uso das águas do rio local tem sido o 
principal fator de contato para contaminação. Pela tabela 1, observamos que a verminose tem ocorrido em grande escala e ainda não foi controlada. Medidas tomadas pelo poder público tem tido uma pequena diminuição dos casos, porém ainda não conseguiu atingir os patamares desejados para o bem estar das comunidades.

Segundo Marques (2004), nenhum método isolado é capaz de controlar a esquistossomose, e todo programa de controle deve considerar a necessidade de uma aplicação multidisciplinar dos métodos existentes.

A ascaridíase, com um total de 139 casos, é uma verminose transmitida pelo verme Ascaris lumbricóides, também conhecido como lombriga, parasita o intestino humano e sua contaminação se da pela ingestão de alimentos e água contaminada diretamente pelos dejetos, onde a ingestão destas águas ou a ingestão de alimentos de forma crua (Brasil, 2006). Alimentos que foram irrigados com água contaminada se caracterizam como as principais formas de transmissão desta verminose nos distritos estudados. O homem é o seu único hospedeiro onde o ciclo do verme se completa, adquirindo a doença ao ingerir ovos do verme em verduras mal lavadas e água contaminada.

O tratamento com medicamentos que eliminam os vermes é muito eficiente. A prevenção consiste na instalação de redes de esgotos, construção de fossas sépticas e educação sanitária, criando hábitos de higiene pessoal (lavar as mãos antes de tocar alimentos ou de comer, etc.) (Linhares, 2005).

A leptospirose aparece em quarto lugar no quantitativo de incidências com um total de 55 casos observados nos quatro distritos estudados, sendo sua maior incidência no distrito de Santo Antônio do Canaã com 21 casos da doença

A doença é transmitida por uma bactéria do gênero Leptospira sendo transmitida ao homem por animais como roedores, suínos, caninos e bovinos, sendo que a bactéria pode sobreviver nos rins destes animais sem causar doença e depois excretados pela urina ao meio ambiente (Veronesi \& Focaccia, 1997). O doente apresenta febre alta, calafrios, dor de cabeça, muscular e articular. É necessário atendimento para evitar complicações renais e hepáticas (LinhareS, 2005).

A malária, com 36 casos, aparece em quinto lugar no quantitativo de incidências observadas nos quatro distritos estudados, sendo que sua incidência aparece nos quatro distritos de forma equiparada.

A doença ocorre em regiões tropicais onde é transmitida ao homem pela picada do mosquito do gênero Anopheles, infestado por um protozoário de nome plasmódio. $\mathrm{O}$ 
ciclo de vida do plasmódio se completa com a participação de dois hospedeiros um definitivo o mosquito e outro intermediário o homem (Lopes \& Lopes, 1987).

Segundo Paulino (2004), quando o mosquito transmissor da malária pica um indivíduo, injeta-lhe um pouco de saliva que contém substâncias anticoagulantes. Caso o mosquito esteja infectado, juntamente com a saliva injetados esporos infestantes dos plasmódios. Esses esporos alcançam a corrente sangüínea humana e se instalam em órgãos diversos. Após o período de incubação, os esporos retornam à corrente sangüínea e penetram nas hemácias, onde se reproduzem assexuadamente. As hemácias então se rompem e liberam no sangue novos plasmódios, que passam a infectar novas hemácias sadias, repetindo-se o processo.

A intoxicação exógena aparece em sexto lugar no quantitativo de incidências com um total de 24 casos observados nos quatro distritos estudados, sendo sua incidência é vista principalmente nos distritos de Várzea Alegre e Santo Antônio, que possuem uma maior quantidade de cultivo de tomate, legume que exige para sua produção um grande contingente de produtos agrotóxicos, o que caracteriza o índice de intoxicações observadas.

Os agrotóxicos ou defensivos agrícolas são substâncias que vêm sendo cada vez mais utilizadas na agricultura e na saúde pública, podendo ou não oferecer perigo para o homem, dependendo da toxicidade, do grau de contaminação e o tempo de exposição durante sua aplicação, sendo o principal problema está na sua utilização indiscriminada, sem qualquer preocupação com a segurança (Lopes, 1997).

Os agrotóxicos que mais causam preocupação em termos de saúde humana são os inseticidas organofosforados e carbamatos, os piretróides e os organoclorados, os fungicidas ditiocarbamatos e os herbicidas fenoxiacéticos $(2,4 \mathrm{D})$, glifosato e paraquat Inseticidas organofosforados e carbamatos (Trapé, 1995).

O trabalho agrícola exige do homem proteções muitas vezes não utilizadas, e podemos citar como a utilização de EPI (equipamento de proteção individual) que é desconsiderada pelo agricultor. Na produção de olerícolas, é necessário muitas vezes de altas doses de pulverizações contra pragas e doenças que acometem as culturas, principalmente a cultura do tomate. O distrito de Várzea Alegre é considerado o maior produtor de tomate do estado, e um dos maiores produtores do Brasil. Santa Teresa desponta como um grande produtor deste legume e esta cultura é tida como a que mais exige proteção com agrotóxicos de todas as culturas existentes no planeta. $\mathrm{O}$ desconhecimento ou mesmo por acreditar que a intoxicação não vai lhe acometer, o 
agricultor prefere não usar os EPIs pois estes causam um grande incomodo e principalmente em dias de sol, tornam-se muito desconfortáveis pelo calor ambiental. A prática contínua de não usar EPI acaba com intoxicações agudas, e a permanência leva a intoxicação crônica com danos irreparáveis a saúde humana.

A leishmaniose aparece em sétimo lugar no quantitativo de incidências com um total de 23 casos observados nos quatro distritos estudados, sendo sua maior incidência no distrito de Várzea Alegre com 13 casos da doença muito superior aos outros distritos estudados.

A doença se manifesta na forma cutânea ou visceral sendo transmitida ao homem pela picada de um inseto do gênero Phlebotomus e do gênero Lutzomya chamado de mosquito palha ou birigui que infestado, introduz no indivíduo um protozoário conhecido como Leishmania da família dos Trypanosomatidae. A forma cutânea é transmitida pela Leishmaniose tegumentar americana conhecida também como Úlcera de Bauru e a visceral ou Calazar transmitida pela Leishmaniose visceral (FUNASA, 1999).

Segundo Linhares (2005) o protozoário penetra no indivíduo pela saliva e se reproduz na pele, na qual causa lesões, que a seguir, aparecem também na mucosa da boca, nariz e na faringe. A profilaxia consiste na luta contra o mosquito e já existe uma vacina desenvolvida por cientistas brasileiros.

A hepatite A aparece em oitavo lugar no quantitativo de incidências com um total de 17 casos observados nos quatro distritos, sendo que sua incidência é equiparada nos distritos estudados.

A doença é causada pelo vírus HVA sendo transmitida de uma pessoa a outra através de água ou alimentos contaminados principalmente frutos do mar e alguns vegetais, a incidência da doença se faz presente em locais em que o saneamento básico é precário ou não existe (Spiller, 2010).

O vírus da Hepatite A pertence a família Picornaviridae, gênero Hepatovírus, espécie Hepatitis A vírus, e anteriormente foi classificado como "enterovírus humano 72”. Trata-se de vírus muito estável, apresentando elevada resistência ao calor, suportando temperaturas de $60^{\circ} \mathrm{c}$ por 10 minutos. Também é resistente a condições de pH baixo. Só se conhece um único sorotipo do vírus da hepatite A. (Trabulsi, 2008).

A tuberculose aparece em nono lugar no quantitativo de incidências com um total de 13 casos observados nos quatro distritos estudados, ocorrendo nos quatro distritos de forma equiparada. 
A doença é causada por um bacilo de nome Mycobacterium tuberculosis conhecido também por bacilo de Koch. É transmitida de pessoa para pessoa pela inalação de gotículas que contém ao menos duas células do bacilo, sendo que os ambientes que possuem risco superior de tuberculose são aqueles que possuem pessoas sintomáticas da doença (Gwon, Shu, Ying, 2004).

O tratamento típico da tuberculose envolve a administração de doses diárias de isoniazida e rifampina por dois meses, seguida de doses bissemanais, por um período total de noves meses. Esse tratamento promove a erradicação dos bacilos da tuberculose e impede a emergência de organismos resistentes aos fármacos originalmente usados no tratamento. (Madigan, 2010).

Tabela 1 - Dados coletados dos quantitativos de doenças ocorridas por distrito na baixada do município de Santa Teresa

\begin{tabular}{|c|c|c|c|c|c|c|c|c|c|c|c|c|}
\hline \multirow[b]{2}{*}{ Doença } & \multicolumn{6}{|c|}{ Várzea Alegre } & \multicolumn{6}{|c|}{ Vinte e Cinco de Julho } \\
\hline & 2006 & 2007 & 2008 & 2009 & 2010 & Total & 2006 & 2007 & 2008 & 2009 & 2010 & Total \\
\hline Malária & 0 & 0 & 8 & 0 & 0 & 8 & 0 & 0 & 4 & 8 & 0 & 12 \\
\hline Leishmaniose & 4 & 6 & 1 & 2 & 0 & 13 & 0 & 1 & 0 & 0 & 1 & 2 \\
\hline Esquistossomose & 25 & 22 & 21 & 20 & 18 & 106 & 18 & 13 & 13 & 12 & 10 & 66 \\
\hline Hepatite A & 3 & 0 & 0 & 0 & 2 & 5 & 2 & 0 & 0 & 0 & 0 & 2 \\
\hline Leptospirose & 4 & 0 & 2 & 1 & 0 & 7 & 14 & 0 & 0 & 0 & 0 & 14 \\
\hline Intox. Exógena & 0 & 0 & 4 & 4 & 1 & 9 & 0 & 0 & 0 & 2 & 0 & 2 \\
\hline Ascaridíase & 12 & 12 & 8 & 7 & 5 & 44 & 8 & 8 & 5 & 5 & 4 & 30 \\
\hline Ancilostomíase & 30 & 22 & 28 & 20 & 20 & 120 & 25 & 19 & 18 & 18 & 17 & 97 \\
\hline \multirow[t]{2}{*}{ Tuberculose } & 1 & 0 & 1 & 1 & 1 & 4 & 4 & 0 & 0 & 0 & 0 & 4 \\
\hline & \multicolumn{6}{|c|}{ Santo Antônio do Canaã } & \multicolumn{6}{|c|}{ São João de Petrópolis } \\
\hline Doença & 2006 & 2007 & 2008 & 2009 & 2010 & Total & 2006 & 2007 & 2008 & 2009 & 2010 & Total \\
\hline Malária & 4 & 0 & 4 & 4 & 0 & 12 & 0 & 4 & 0 & 0 & 0 & 4 \\
\hline Leishmaniose & 0 & 2 & 1 & 0 & 0 & 3 & 0 & 1 & 0 & 2 & 2 & 5 \\
\hline Esquistossomose & 22 & 22 & 21 & 19 & 17 & 101 & 21 & 20 & 21 & 20 & 16 & 98 \\
\hline Hepatite A & 1 & 0 & 0 & 3 & 0 & 4 & 5 & 0 & 0 & 1 & 0 & 6 \\
\hline Leptospirose & 16 & 2 & 2 & 1 & 0 & 21 & 11 & 2 & 0 & 0 & 0 & 13 \\
\hline Intox. Exógena & 0 & 0 & 3 & 4 & 2 & 9 & 0 & 0 & 2 & 0 & 2 & 4 \\
\hline Ascaridíase & 9 & 9 & 8 & 4 & 4 & 34 & 8 & 8 & 7 & 4 & 4 & 31 \\
\hline Ancilostomose & 22 & 20 & 19 & 18 & 16 & 95 & 25 & 22 & 21 & 19 & 16 & 103 \\
\hline Tuberculose & 0 & 1 & 2 & 1 & 0 & 4 & 0 & 0 & 0 & 0 & 1 & 1 \\
\hline
\end{tabular}

\section{CONCLUSÃO}

Ficou diagnosticado que as doenças que mais acometem a população da baixada terezense, causadas pela poluição da água, ar e solo, são próprias dos municípios 
considerados como agrícolas, sustentadas pela não observância dos hábitos de higiene e a falta de saneamento básico para a população.

A necessidade de informação da população, o apoio das autoridades e a participação da própria população na preservação do meio, propõem o recondicionamento destes cidadãos para um meio equilibrado e consciente, a partir de um programa de educação ambiental viável à realidade local.

\section{REFERÊNCIAS}

Andrade, J. S. F. Analogias em Medicina: parte IV. Rev Med. 21(1): 86-88, Minas Gerais, 2011.

Aguiar, A. A. G., Apostila de Educação ambiental, Faculdade do Vale do Jurema, Módulo-01, Juína, MT, 1998.

Brasil. Ministério da Saúde. Sec. de Vigilância em Saúde. Esquistossomose. 2005.

Brasil. Fundação Nacional de Saúde. Manual de Saneamento. 4ed. Brasília, 2006. 408p.

Carvalho, A. R. \& Oliveira, M. V. C. 1997. Princípios básicos do saneamento do meio. São Paulo: SENAC. 328p.

FUNASA. Endemias: informações para multiplicadores em ações de educação sanitária. Ministério da Saúde, Coordenação regional do Espírito Santo, E.S., 1999. 59p.

Gwon, H. W.; Shu, C. L.; Ying, H. Ti. Polymerase chain reaction used for the detection of airborne Mycobacterium tuberculosis in health care settings. American Journal of Infection Control. v. 32, n. 1, p 17-22, 2004.

Linhares, S.; Gewandsnajde, F. Biologia, volume único, São Paulo: Editora Àtica, 2005.

Lopes, A. C. Intoxicações e envenenamentos, Universidade Estadual de Campinas, São Paulo: Copyright, 1997.

Lopes, S. G. B. C.; Lopes, P. C. Curso completo de Biologia. São Paulo: Saraiva, 1987. 332p.

Madigan, M. T.; Martinko, J. M.; Dunlap, P. V.; Clark. D. P.. Microbiologia de Brock, Porto Alegre: Editora Artmed, 2010.

Marques, F. Memórias do Instituto Oswaldo Cruz, Centro de Pesquisas Gonçalo Moniz (CPqGM), Bahia: 2004.

Medina, M. N. \& Santos E. C. Educação Ambiental: Uma Metodologia Participativa de Formação, $3^{\text {a }}$ Edição, Petrópolis, R.J.: Ed. Vozes, 2003. 
Mendes, L. A. A. Diretrizes para Implantação da Gestão Ambiental na Universidade do Estado do Rio de Janeiro - Dissertação de mestrado, Campus Francisco Negrão de Lima, Rio de Janeiro: FEN/UERJ, 2005. 111p.

Paixão, M. V. S. A Atuação da escola na formação social de jovens do ensino médio no município de Santa Teresa, Espírito Santo, Brasil. Tese de doutorado. UAA, Assunção, 2009. 122 p.

Paulino W. R. Biologia, 9a edição, São Paulo: Editora Ática, 2004.

Philippi, Jr. A. \& Malheiros, T. F. Saneamento e saúde pública: integrando homem e meio ambiente. In: Philippi Jr, A. Saneamento saúde e ambiente: fundamentos para um desenvolvimento sustentável. Barueri, SP: Manole, 2005.

Rossi-Espagnet, A; Goldstein, G.B \& Tabibzadeh, I. Urbanization and health in developing countries: a challenge for health for all. World Health Stat. Q., 44(4):186244, 1991.

Sirkis, A. et al. Meio ambiente século 21: 21 especialistas falam da questão ambiental nas suas áreas de conhecimento, prefácio de Marina silva, $4^{a}$ ed. Campinas, SP: Armazém do Ipê( Autores Associados), 2005.

Spiller, C. Doenças causadas pela poluição ambiental, Juína-MT, 2010.

Tessari, A. L. Educação Ambiental: conceitos para fazer. Textos acadêmicos, São Paulo: Copyright, 2003.

Trabulsi, L. R.; Alterthum, F. Microbiologia, $5^{\text {a }}$ edição, São Paulo: Editora atheneu, 2008.

Trapé, A. Z. Doenças relacionadas a agrotóxicos :um problema de saúde pública, Tese Doutorado - Unicamp, Campinas, 1995.

VasconceloS, L. C. S. et al. A chuva ácida em sala de aula. In: ANAIS DO XII Simpósio Brasileiro de Geografia Física Aplicada. Natal/RN, 2007. P.1-16.

Veronesi, R.; Focaccia, R. Tratado de infectologia. Rio de Janeiro: Atheneu, 1997. 